\title{
Territorio y patrimonio rural en las sierras de Cazorla, Segura y las Villas. Nuevas perspectivas de investigación
}

Eduardo Araque Jiménez | Área de Análisis Geográfico Regional, Universidad de Jaén

URL de la contribución <www.iaph.es/revistaph/index.php/revistaph/article/view/3387>

\section{RESUMEN}

En el extremo oriental de la provincia de Jaén, en el parque natural Sierras de Cazorla, Segura y las Villas, tanto por la abundancia y diversidad de recursos naturales, como por la secular forma de explotación de esos recursos, los aprovechamientos forestales se conformaron históricamente como la actividad económica hegemónica en estos macizos.

Junto a ellos desde comienzos del siglo XX empezó a despuntar con fuerza la explotación de una cabaña ganadera integrada mayoritariamente por ejemplares de ovino y caprino. Frente a la importancia de las actividades silvo-pastoriles, la agricultura ocupó un plano secundario, en parte por los propios condicionantes naturales a los que se enfrentaba la expansión del terrazgo y, en parte, por las trabas jurídicas que se presentaban en un ámbito donde era dominante la propiedad pública del suelo.

En este trabajo se describen de forma resumida las características esenciales de los aprovechamientos reseñados y se sugieren algunas líneas de investigación encaminadas a un conocimiento más exhaustivo de la base patrimonial a la que dieron origen. Todo ello con el fin de incorporar esos restos a un programa de interpretación patrimonial enfocado a la educación en valores ambientales respetuosos con el territorio y la cultura serrana.

\section{Palabras claves}

Parque natural Sierras de Cazorla, Segura y las Villas | Sierras de Cazorla, Segura y las Villas | Jaén (Provincia), España, Andalucía | Reservas de la biosfera | Patrimonio rural | Patrimonio forestal | Montes | Ganadería | Agricultura | 


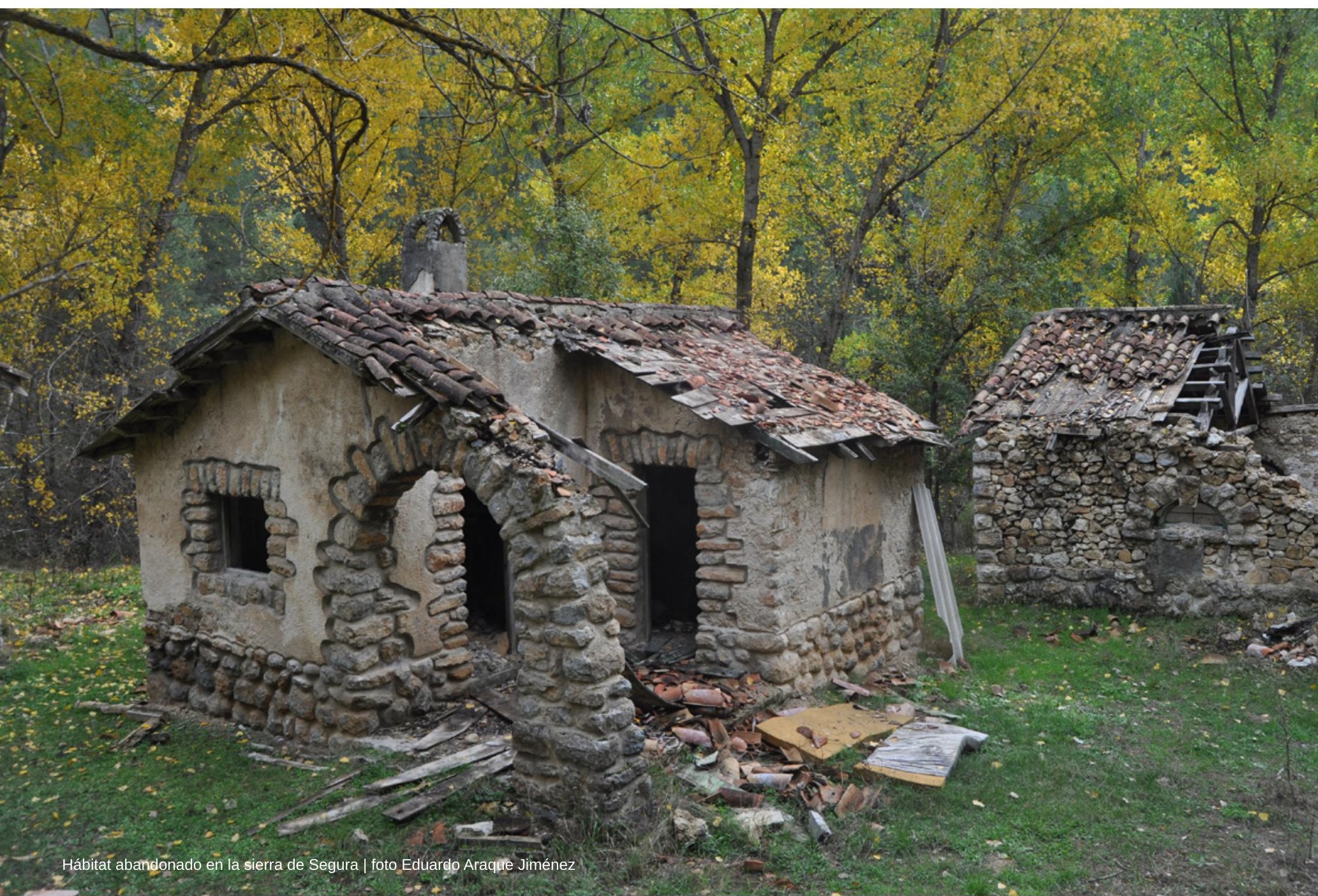




\section{INTRODUCCIÓN}

1

Aunque ambas sierras forman parte de un mismo conjunto orográfico, integrado en el sector prebético del frente externo de la cordillera bética, desde el punto de vista político-administrativo se consideran comarcas independientes. La sierra de las Villas o de las Cuatro Villas es, en realidad, un mero apósito de la unidad geológica de la sierra de Cazorla. Se trata de un monte cuya propiedad y aprovechamiento compartieron históricamente los ayuntamientos de Villacarrillo, Villanueva de Arzobispo, Iznatoraf y Sorihuela del Gudalimar. A pesar de esta diversidad, en el último medio siglo ha sido muy frecuente identificar la totalidad del macizo con el equívoco nombre de sierra de Cazorla.
Las sierras de Cazorla, Segura y las Villas ${ }^{1}$, en el extremo oriental de la provincia de Jaén, constituyen uno de los ámbitos serranos andaluces de mayor singularidad geográfica. La disposición de esta porción del arco prebético a barlovento de las corrientes perturbadas del oeste que penetran por el valle del Guadalquivir da origen a copiosas precipitaciones anuales (en varias estaciones meteorológicas se superan ampliamente los $1.000 \mathrm{~mm}$ de lluvia anuales), lo que hace de este enclave montañoso el principal nudo hidrográfico de la mitad meridional de la Península Ibérica. Además del Guadalquivir y Segura, aquí tienen su origen algunos de los afluentes de cabecera más caudalosos de esas dos grandes arterias fluviales que recorren y dan vida a buena parte del sur y sureste peninsular.

Semejante abundancia de precipitaciones en unos contextos regionales extremadamente secos o semiáridos hizo que desde un primer momento la política hidráulica fijara toda su atención en estas sierras. A comienzos del siglo $X X$, cuando empezaron a formularse los primeros planes de obras hidráulicas en nuestro país (GIL OCINA, 2001), tanto la Sierra de Segura como la de Cazorla se convirtieron en uno de los escenarios peninsulares más apropiados para la localización de distintos canales de riego y embalses de regulación, imprescindibles para atender las crecientes demandas de agua y de electricidad provenientes de los fértiles campos y de las incipientes aglomeraciones industriales localizadas en los grandes valles próximos.

Por otra parte, esa prodigalidad de las precipitaciones está en la base de la exuberancia con la que se manifestó históricamente la abundante y diversa vegetación natural que recubre estas montañas, entre la que desde antiguo despertó un especial interés el pino laricio o salgareño (Pinus nigra), conocido también como "pino de Segura", por sus variadas utilidades y enormes posibilidades de explotación mercantil. De hecho, durante la mayor parte de los tres últimos siglos el aprovechamiento de esa y de otras especies maderables, así como de los restos leñosos de todas ellas, se convirtió en una actividad hegemónica dentro de la economía agraria serrana por su alta capacidad para generar riqueza y empleo, aunque no siempre se le sacara a estos recursos el suficiente partido en pos de un verdadero desarrollo territorial justo y equitativo.

Junto a los aprovechamientos forestales, desde comienzos del siglo $\mathrm{XX}$ empezó a despuntar con fuerza la explotación de una cabaña ganadera integrada mayoritariamente por ejemplares de ovino y caprino, que poco a poco fue ganando peso específico en la mayor parte de los municipios serranos hasta llegar a convertir a toda esta zona montañosa en uno de los principales enclaves ganaderos de la región andaluza. La abundancia y diversidad de las especies pastables que florecían en las amplias áreas abiertas al pas- 
toreo en estos macizos propiciaron este incremento de efectivos ganaderos, cuyo sostenimiento fue posible por el establecimiento de un sistema estacional de desplazamiento de pastores y ganados entre las altas cumbres de las sierras de Segura y Cazorla y las más bajas estribaciones de Sierra Morena, que a este respecto funcionaron como sendos pastaderos de extremo.

Frente a la importancia de las actividades silvo-pastoriles, la agricultura ocupó secularmente un plano secundario, en parte por los propios condicionantes naturales a los que se enfrentaba la expansión del terrazgo, y, en parte, por las restricciones jurídicas que aquí se daban a la posesión y disfrute de la tierra. Porque esa es otra de las grandes singularidades que ofrecen estos ámbitos montañosos en el contexto andaluz: la extraordinaria relevancia de la propiedad municipal y, sobre todo, de la estatal, frente a la propiedad privada. Ambas formas de propiedad pública alcanzaron desde antiguo cotas realmente espectaculares que condicionaron sobremanera la libertad de uso de un bien tan escaso en la montaña mediterránea como la tierra apta para el cultivo. Aunque no podemos extendernos sobre el particular, baste saber que fue el proceso desamortizador de Madoz, tan decisivo en el resto de Andalucía de cara a la privatización de la tierra, el que sirvió aquí para afianzar sobre bases mucho más sólidas la propiedad pública de los montes, que no sólo se mantuvieron al margen de la almoneda, sino que se deslindaron y amojonaron para materializar el dominio que sobre ellos poseían el Estado y los ayuntamientos, procurando excluir de sus dominios toda clase de uso agrícola.

De acuerdo con lo expuesto, en este trabajo nos proponemos describir de una forma muy resumida los variados aprovechamientos que históricamente se llevaron a cabo en estas sierras orientales jiennenses, resaltando sus aspectos más relevantes y la base patrimonial que hizo posible el sostenimiento de unos peculiares modos de explotación de sus múltiples recursos naturales. Al mismo tiempo trataremos de sugerir algunas líneas de investigación susceptibles de servir de base a programas más amplios encaminados a la interpretación patrimonial, enfocados no tanto desde la perspectiva de la exposición turística como de la educación en valores ambientales respetuosos con el territorio y la cultura serrana.

\section{UN PATRIMONIO FORESTAL EXCEPCIONAL}

Aunque la explotación de los recursos forestales de las Sierras de Cazorla, Segura y las Villas está documentada desde antiguo (VALLVÉ BERMEJO, 1969), no fue hasta el primer tercio del siglo XVIII cuando alcanzó unas ciertas dimensiones que no harían más que incrementarse con el transcurso del tiempo. La necesidad de disponer de grandes cantidades de vigas de madera y otro tipo de piezas para la construcción de la Real Fábrica de Tabacos de 
Sevilla impulsó al Ministerio de Hacienda a desplegar todos los mecanismos técnicos y jurídicos que tenía a su alcance para hacerse con el control de tan suculento recurso. Poco después el Ministerio de Marina siguió los pasos al de Hacienda, de modo que no quedó más remedio que establecer un régimen alterno de aprovechamientos madereros mediante el cual cada año uno de los dos entes ministeriales explotaba y extraía los troncos de arbolado de estas sierras y los transportaba por vía fluvial hasta Sevilla. Cuando la madera pertenecía al Ministerio de Marina, desde la capital sevillana se reenviaba, bien en barcos bien por vía terrestre, hasta el arsenal gaditano de la Carraca, donde se empleaba en la construcción de distintas partes de los navíos de la armada española (QUINTERO GONZÁLEZ, 2004; LÓPEZ ARANDIA, 2012). No sin tensiones ni conflictos, este régimen se mantuvo vigente hasta bien entrado el siglo XIX, cuando se abolieron todas las jurisdicciones privativas, y muy especialmente el particular régimen de administración de la denostada provincia marítima de Segura de la Sierra (CRUZ AGUILAR, 1981).

Tras unos años en los que se redujeron de forma considerable las cortas de arbolado, a mediados del siglo XIX se inició una etapa radicalmente diferente a la anterior, durante la cual crecieron de un modo desorbitado las extracciones madereras de los montes. La enorme demanda que generaron actividades en plena expansión en Andalucía como el establecimiento del tejido ferroviario, la apertura de numerosos pozos mineros o la construcción de miles de viviendas, por ese mismo orden de importancia, sometieron a los montes a una intensa presión que tuvo consecuencias aciagas para la cubierta vegetal, que desapareció a un ritmo vertiginoso en numerosos tranzones, dando paso a fenómenos erosivos de una cierta consideración.

A diferencia de la fase anterior, en ésta la madera se elaboró casi por completo en el interior de los montes, como sucedió con las traviesas para el ferrocarril, o bien sufrió una primera transformación antes de ser empleada en la entibación de los pozos mineros (apeas) o en la construcción del armazón de las nuevas viviendas (vigas, tablas, etc.). Numerosas serrerías volantes distribuidas por los montes se consagraron durante años a atender las peticiones de las múltiples compañías y particulares que se dedicaban al comercio maderero a mayor o menor escala. La intensa actividad que desplegaron todas ellas resultó sumamente eficaz desde una perspectiva económica y social por su capacidad de generación de empleo, lo que redundó en una mejora generalizada de las condiciones de vida de una parte de la población serrana.

Después de la severa reducción que experimentaron las extracciones de madera a partir de la segunda década del siglo XX y, sobre todo, durante la etapa republicana, de nuevo al finalizar la guerra civil se recuperaron los 
ritmos de producción tradicionales, e incluso llegaron a superarse ampliamente en los momentos de máximo auge de la autarquía. La urgencia en la reconstrucción del tendido ferroviario así como la reparación de una parte del material rodante y de múltiples instalaciones ferroviarias seriamente dañadas durante la contienda impulsaron al Estado a establecer los mecanismos legales para destinar toda la producción de madera de las sierras de Segura y Cazorla a este fin estratégico de primer orden, erigiéndose RENFE a partir de entonces en la principal beneficiaria de este recurso.

Junto a la madera, en el último cuarto del siglo XIX emergieron con fuerza otros aprovechamientos que en las estadísticas oficiales se tildaban de secundarios por su menor capacidad de generación de ingresos para las arcas públicas, pero que, sin excepciones, desempeñaban un papel social y ecológico trascendental al proporcionar rentas y empleo a partir de la eliminación de los despojos procedentes de las cortas de arbolado y otra parte de la biomasa acumulada en los montes. Todos estos residuos vegetales constituían un excelente combustible que podía ser pasto de las llamas en cualquier momento, por lo que su eliminación resultaba una excelente labor de profilaxis forestal ya que contribuía en gran medida a la disminución del riesgo de incendio en los montes.

Los incendios forestales se han constituido históricamente en la mayor amenaza a los paisajes serranos | foto Luis Colmenero

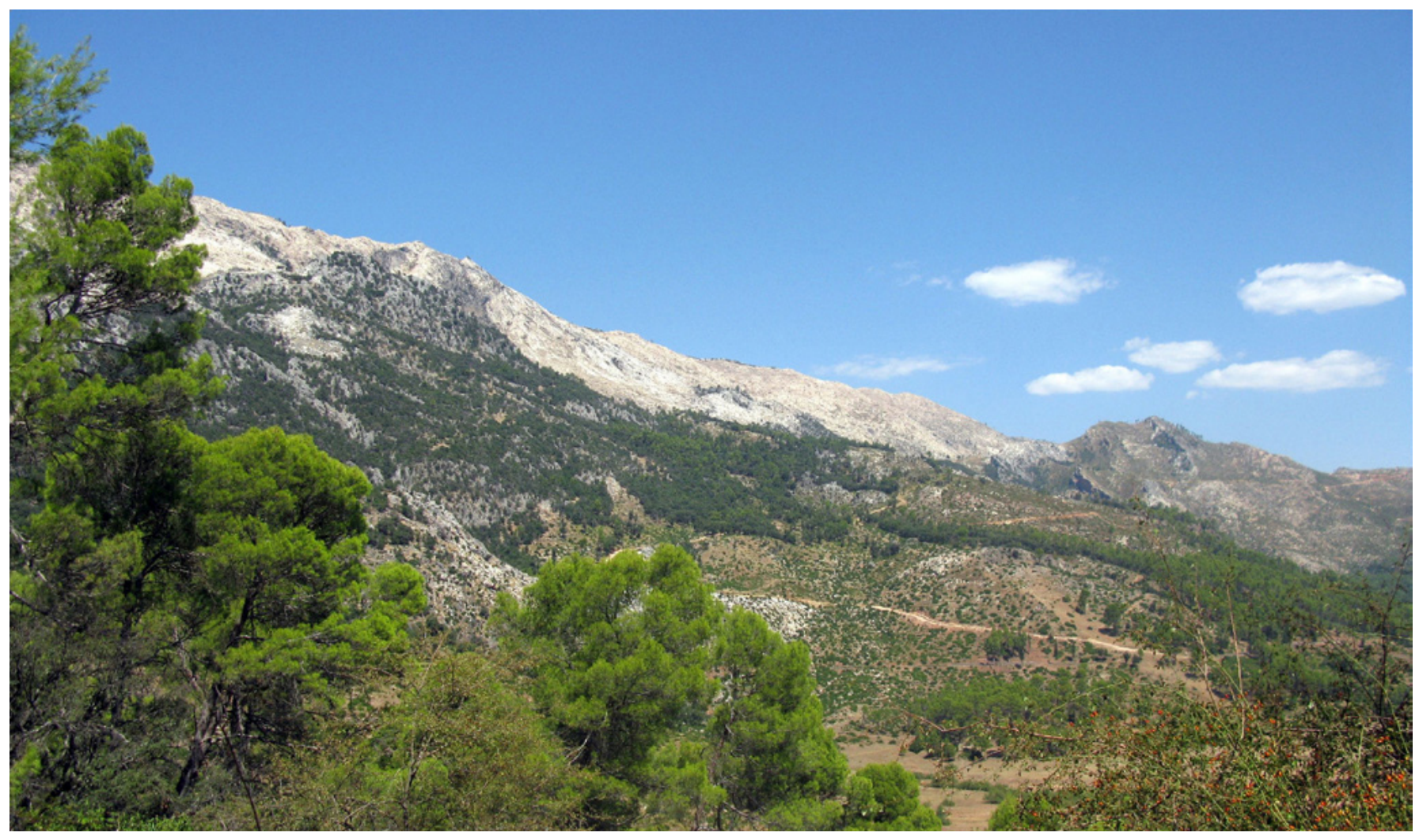


Así sucedía, por ejemplo, con los tocones y el ramaje que se obtenían tras las cortas del pinar, cuyo alto contenido en resina propiciaba la recolección de estos restos de los cuales se extraía la pez o alquitrán vegetal, un producto muy demandado en todo el litoral mediterráneo para el calafateado de las embarcaciones de madera. Otra parte de los restos leñosos, en este caso procedentes de las podas y descuajes del arbolado, se utilizó tradicionalmente en la fabricación de carbón vegetal, muy valorado cuando se empleaban aquellas quercineas más abundantes en la zona como la encina, el quejigo o el roble melojo. No obstante cuando empezaron a escasear estas especies nobles se recurrió a los pinares defectuosos que, si bien no proporcionaban un carbón de tanta calidad, tenían una fácil salida tanto en el mercado comarcal como en el provincial debido a su extendido uso en los hogares y en los diferentes tipos de hornos artesanales.

Mucho más moderna resulta la obtención de esencias a partir de la cocción de distintas plantas aromáticas y medicinales como la mejorana, el espliego, el tomillo y el romero, cuya expansión en estas sierras se inició en las postrimerías del siglo XIX. La abundancia de plantas y la relativa facilidad de su procesamiento (BARÓ, 1915) empujaron a numerosos habitantes de estas sierras a consagrarse laboralmente a su recolección y a la posterior fabricación de esencias durante los meses veraniegos, una vez que habían concluido las faenas de recolección cerealista (SIMÓN, 1953). De esta forma todos cuantos se ocupaban en estas labores podían obtener unos ingresos suplementarios que nunca venían mal a las depauperadas economías familiares.

Igualmente en el período finisecular podemos situar el arranque de la etapa más floreciente en el aprovechamiento del esparto, auspiciada por el empleo creciente de esta fibra en la confección de distintos enseres domésticos y, sobre todo, en la fabricación de capachos para la industria de extracción de aceite, que empezaba a proliferar en la provincia de Jaén en ese momento (MOYA GARCÍA, 2007). Durante muchos años el trabajo del esparto no traspasó el ámbito de la unidad familiar, donde todos los individuos con aptitudes se dedicaban al trenzado y preparación de la fibra, que luego era vendida a los intermediarios locales para su posterior distribución comercial.

Por último, en este rápido repaso a la explotación de los principales recursos vegetales no queremos omitir la extracción de resina que durante algunos años de la segunda mitad del siglo XX se llevó a cabo en distintos montes de la Sierra de Cazorla donde más abundaba el pino negral (Pinus pinaster) (MOLINA RODRÍGUEZ, 1946). La extrema escasez de este recurso en el mercado nacional obligó a poner en marcha la explotación resinera de estos montes en plan experimental, si bien muy pronto hubo que abandonarla, entre otras cosas porque el aprovechamiento resinero se demostró incompatible con el maderero, y se optó abiertamente por este último, cuyo aprovisionamiento se consideraba mucho más urgente. 
Además de la biomasa, los montes fueron objeto de otro tipo de aprovechamientos relacionados con la naturaleza del sustrato litológico. El más extendido por estas sierras, dada la abundancia de materia prima, fue la fabricación de cal mediante la cocción de pequeños fragmentos de roca caliza (GARRIDO GONZÁLEZ; GARRIDO SÁNCHEZ, 2003). La proliferación de hornos de cal (caleras) estuvo íntimamente relacionada con el notable desarrollo de obras de mampostería que llevaban aparejadas distintas actuaciones forestales, particularmente los diques transversales a los cauces, que formaban parte de los trabajos de corrección hidrológico-forestal, y los muros de contención para defensa de las vías de saca de los montes, que tanto proliferaron a partir de la segunda década del siglo XX. La obtención de yeso, circunscrita a la zona de contacto de la sierra de Cazorla con el pasillo del Guadiana Menor, era muy similar pero algo más compleja que la de la cal. Por otra parte, su uso estuvo siempre más vinculado a la decoración de viviendas, tanto a su revestimiento externo como a las obras interiores, por lo cual su comercialización traspasó ampliamente los estrechos límites del mercado comarcal para extenderse a los ámbitos provincial y regional.

El conjunto de estas actividades vinculadas a las funciones de producción de los montes generó un valioso patrimonio material que sigue siendo en gran parte desconocido en nuestros días ${ }^{2}$. No es sólo que apenas se haya avanzado en el estudio de los métodos de transformación y comercialización, o que aún estemos muy lejos de conocer cómo se distribuían por el territorio cada una de estas actividades, es que, salvo excepciones puntuales, ni siquiera se han localizado los restos materiales que han quedado de una buena parte de ellas. Por esta razón no podemos pensar por el momento en su incorporación a programas de interpretación territorial tendentes a poner de manifiesto la enorme diversidad de formas de explotación de los recursos que históricamente cobijaron estas montañas, mucho mayor que la de las campiñas y llanuras próximas, donde comenzaba a afianzarse un régimen de monocultivo agrícola (MORENO FERNÁNDEZ, 2001). Ahora bien, por lo recogido en distintos trabajos de reconocimiento territorial parciales y muy someros (IDÁÑEZ, 1995; NIETO OJEDA, 2006), sabemos que aún es posible identificar muchos de estos elementos a pesar del avanzado estado de descomposición en el que se encuentran.

Igualmente resultan muy poco conocidos los procesos de distribución y transporte hasta el mercado de los productos elaborados o semielaborados con origen en estas sierras. Especialmente llamativa resulta la desatención que hasta la fecha se ha prestado al transporte fluvial de madera, sin duda la actividad de mayor calado social y económico durante siglos. De forma muy superficial se ha estudiado la organización social de los pineros ${ }^{3}$ y las funciones que desempañaban cada grupo de ellos dentro de las conducciones fluviales (IDÁÑEZ, 1999), pero poco sabemos acerca de los denominados ríos flotables o del volumen de piezas transportadas por cada uno de ellos,
2

Además de las funciones de producción, estos montes desempeñaron tradicionalmente otras funciones de protección y recreo que, junto a las labores de gestión, dieron origen a otra fracción patrimonial de un elevado interés por sus grandes potencialidades para un uso lúdico y educativo (ARAQUE JIMÉNEZ, 2011; 2012).

3

Con este nombre se conoce a los trabajadores que participaban en las labores de transporte fluvial de la madera, ocupándose de todas las faenas que hacían posible que las piezas llegaran a su lugar de destino en el tiempo previsto para ello. 


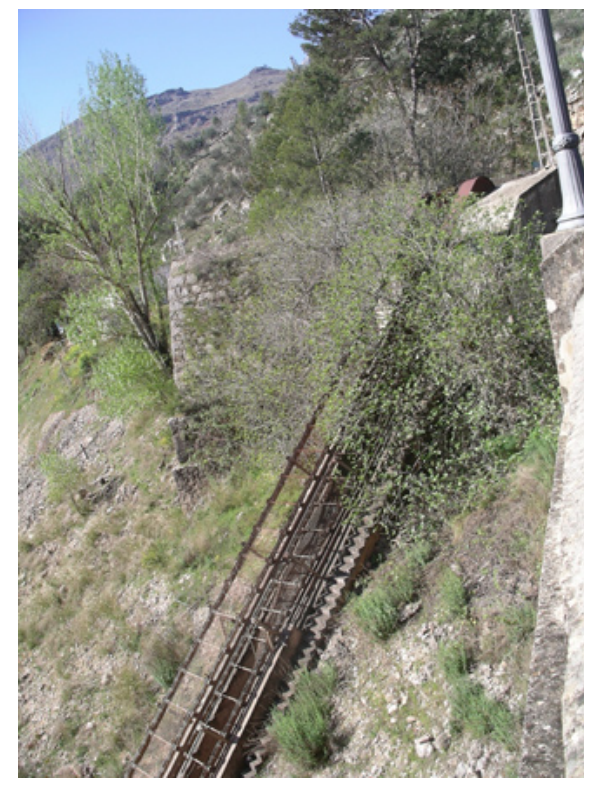

Estado actual del elevador de madera del pantano del Tranco | foto Eduardo Araque Jiménez

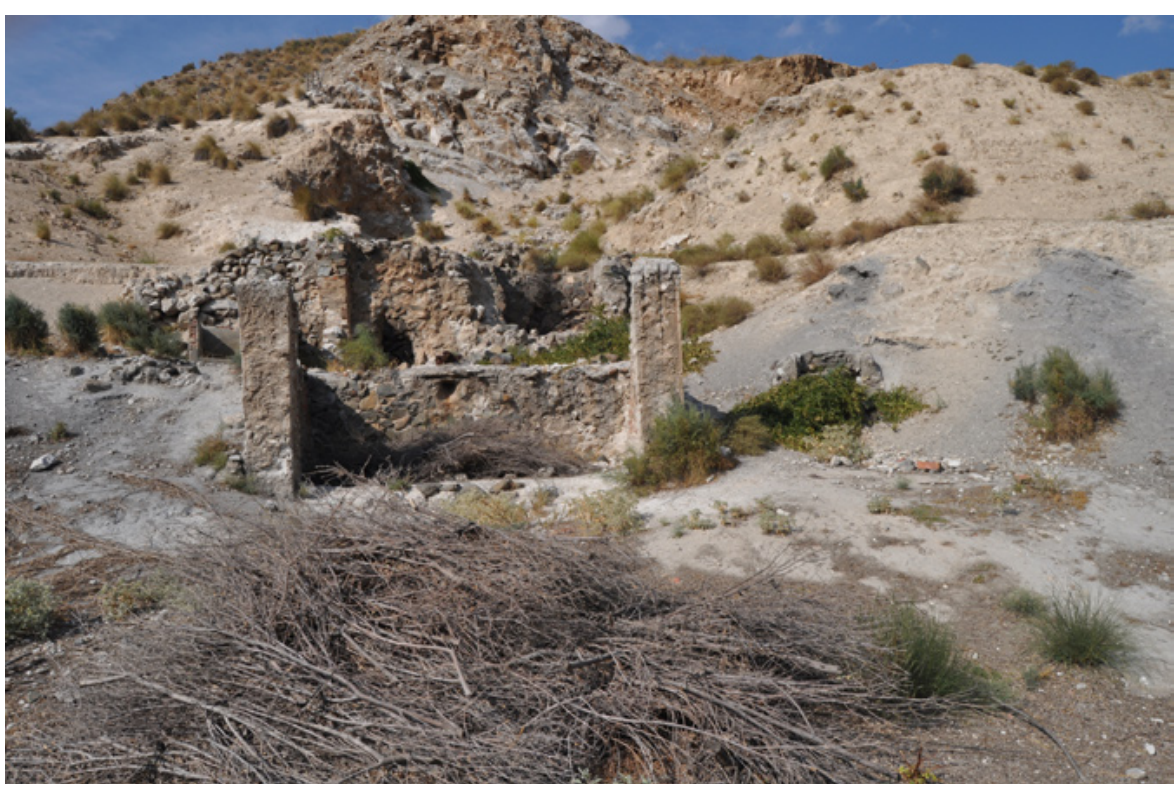

Calera abandonada en la sierra de Cazorla

| foto Eduardo Araque Jiménez

así como de su distribución en el tiempo o los cambiantes puntos de origen y destino de las maderadas.

Por lo que aquí nos interesa, lo más sorprendente es el poco aprecio hasta ahora mostrado hacia algunos restos patrimoniales de inconmensurable valor, entre los que figura en un lugar destacado el elevador de madera del pantano del Tranco. Se trata de un artilugio único en su género en nuestro país, construido en la inmediata posguerra que durante algunos años permitió sortear con éxito la infranqueable barrera que constituía el impresionante muro de esta obra hidráulica. El elevador era, en realidad, una cinta sinfín, provista de ganchos que recogía las piezas que llegaban flotando a través de las aguas del embalse y las elevaba hasta la parte superior del muro de la presa. Una vez allí, la madera podía cargarse en camiones y seguir su camino por vía terrestre, o bien devolverse a las aguas del Guadalquivir a través de un túnel excavado en la parte opuesta de la pared de la presa a la que se encontraba el elevador. Para dar una ligera idea de la eficacia de este artilugio, baste con señalar que durante algunos años llegaron a elevarse por él más de 300.000 piezas de madera (BRIONES, 1946; PUIG, 1960).

\section{LOS ÚLTIMOS TRASHUMANTES. LAS HUELLAS DE LA EXPLOTACIÓN GANADERA DEL TERRITORIO}

El segundo sostén en importancia de la economía agraria serrana fue la ganadería de ovino y caprino, explotada en régimen extensivo mediante un pecu- 
liar sistema de trasterminancia plenamente implantado ya en el siglo XVI, tal y como atestiguan las relaciones topográficas de Felipe II (VILLEGAS DÍAZ; GARCÍA SERRANO, 1976). Según la información contenida en esta fuente, el municipio que con los años llegaría a alcanzar una mayor importancia ganadera, no ya sólo en estas sierras sino en toda Andalucía, Santiago de la Espada (también conocido como Puebla de Santiago o El Hornillo), se había fundado por ganaderos procedentes de Siles y Segura de la Sierra que todos los años se desplazaban con sus rebaños hasta estas altas tierras para que los animales pudieran aprovechar los abundantes pastos que se les ofrecían durante la estación veraniega.

Disponemos de muy pocos datos desagregados por municipios sobre los efectivos que históricamente integraron la cabaña ganadera serrana pero, curiosamente, dando un gran salto en el tiempo, contamos con una serie correspondiente al mentado Santiago de la Espada, que creemos que puede ayudarnos a entender mejor los vaivenes experimentados por este importante ramo de riqueza (ARGÜELLES ÁLVAREZ, 1961). Como puede apreciarse en el gráfico 1, en la primera década del siglo XX este municipio ya contaba con más de 50.000 cabezas de ganado ovino, pertenecientes en su mayoría a la raza autóctona de ovino segureño, a las que había que unir otras 10.000 cabezas de caprino muy mezcladas y alrededor de un millar de cabezas de vacuno. Una década después el ganado lanar ya superaba ampliamente las 63.000 cabezas mientras que el ganado caprino se había duplicado (21.000 cabezas en 1922) y el vacuno se acercaba a las 5.000 cabezas. Desde estos momentos de comienzos de los años veinte el censo de las tres especies comenzó a reducirse paulatinamente hasta tocar fondo a principios de la década de los sesenta, cuando se contabilizaban poco más de 19.000 ejemplares de ovino, alrededor de tres centenares de caprino y menos de un centenar de vacuno.

\section{EVOLUCIÓN DEL GANADO OVINO EN SANTIAGO DE LA ESPADA (1912-1960)}

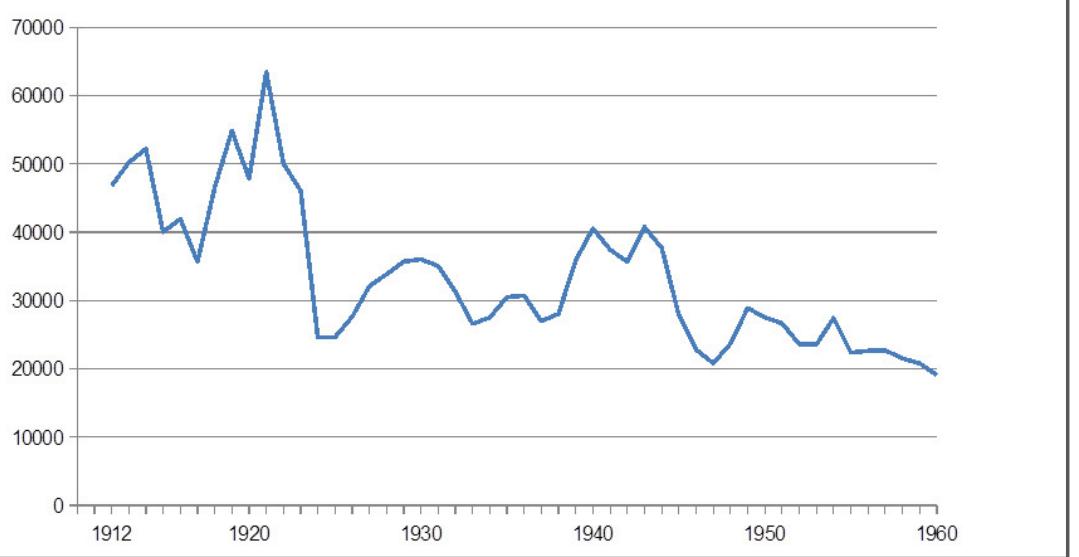


4

Sólo un grupo muy reducido de ganaderos utilizaba las tierras murcianas para la invernada.

\section{5}

Para diferenciarlos de los ganaderos procedentes de Cuenca, a los que se conocían como "serranos", en los municipios de Sierra Morena se denominaban "pontoneros" a la totalidad de los ganaderos procedentes de las sierras de Segura y Cazorla. El calificativo respondía al hecho de que Pontones era la cuna del segundo grupo más importante, tras Santiago de la Espada, de los pastores y rebaños que cada año acudían a Sierra Morena.
En una proporción muy elevada, si pudiéramos cuantificarlo, semejante estado de decadencia se explicaba por la profunda crisis en la que se hallaba inmerso el sistema de explotación trashumante, vigente al menos desde comienzos del siglo XX. No estamos hablando, obviamente, de un sistema similar al que se siguió históricamente en la explotación de las abundantes cabañas soriana, leonesa o conquense, sino de otro de radio mucho más corto que se desarrollaba entre los pastaderos de las porciones más elevadas de las sierras de Segura y Cazorla y el secular invernadero que conformaba toda la cara sur de la porción jiennense de Sierra Morena ${ }^{4}$, completamente privatizada tras la desamortización y consagrada a este uso tan rentable (RUBIO DE LUCAS, 1993).

Con la llegada de los primeros fríos otoñales, generalmente a finales de septiembre, los ganaderos de estas sierras ${ }^{5}$ iniciaban a pie el camino que les conducía hasta las fincas de la porción jiennense de Sierra Morena, cuyos pastaderos habían contratado previamente con sus dueños para toda la invernada, o sea, hasta los últimos días de abril o los primeros de mayo. En ese momento del año se producía el regreso hacia los pastos de altura de los respectivos términos de procedencia de los rebaños. Así un año tras otro hasta que el sistema comenzó a resquebrajarse por la concatenación de varios factores de distinta naturaleza e importancia. El más importante de ellos, a nuestro modo de ver, fue el notable encarecimiento que experimentaron los pastos de invierno en Sierra Morena. La política de repoblación forestal que comenzó a ejecutarse en estos ámbitos montañosos después de la guerra civil (SÁNCHEZ MARTíNEZ et ál., 2008) redujo de un modo apreciable las superficies abiertas al pastoreo en los montes y, ante una demanda creciente de pastos, provocó un alza sensible de los precios a la que no podían hacer frente la mayor parte de los ganaderos cazorlenses y segureños.

Por otro lado, no conviene desdeñar el importante papel que desempeñó la escasa capacidad de reemplazo generacional que caracterizó a la actividad ganadera a partir de los años sesenta, motivada, esencialmente, por la alta tasa de emigración, que se cebó de un modo muy especial sobre la fracción más joven de la población serrana, pero también por la dureza del modo de vida pastoril y por los pocos visos de futuro que ofrecía la explotación ganadera extensiva, incapaz de competir con los modernos sistemas de cría intensiva del ganado que tanto se expandieron en España en esos momentos. Para completar este cuadro decadente hay que hacer alusión a la invasión que sufrieron muchos de los caminos ganaderos tradicionales por los que se desplazaban los ganados y formaban parte sustancial del sistema de explotación. Tanto la repoblación forestal como el avance de los campos de cultivo y otros elementos de la trama urbana vinieron a interceptar esos caminos sin que ninguna autoridad pública hiciera nada por evitarlo, lo que dificultó enormemente el mantenimiento de la cabaña ganadera serrana, que 


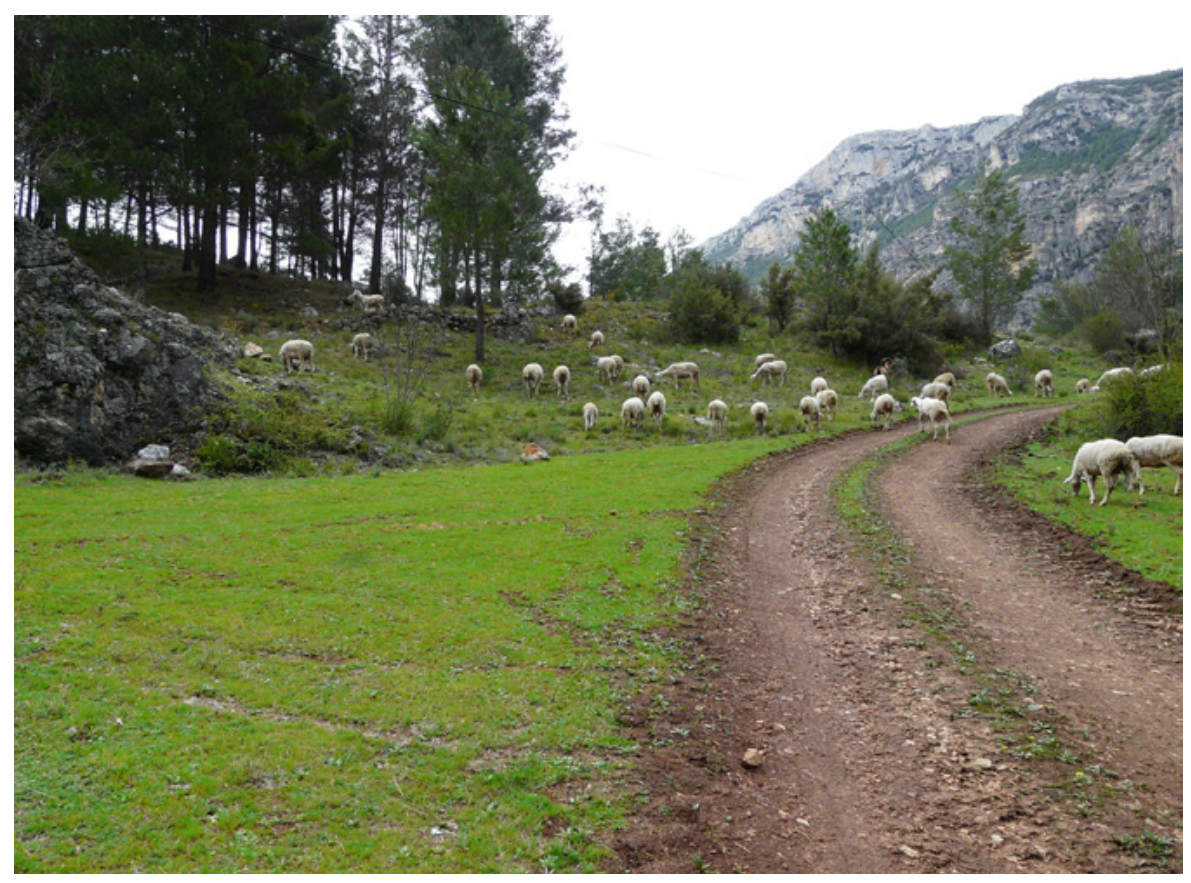

Ganado ovino pastando en el valle del Segura | foto Eduardo Araque Jiménez

por estrictas razones meteorológicas tenía que estar desplazándose continuamente a lo largo del año.

Sólo las fuertes inyecciones económicas en forma de primas ganaderas que introdujo la Política Agraria Común a partir de 1986 fue capaz de conseguir el reverdecimiento de la actividad pecuaria en estas sierras. Tal circunstancia no se tradujo, sin embargo, en la recuperación del viejo sistema de explotación trashumante, que se redujo hasta límites testimoniales, sino en la implantación de uno bien distinto en el que los movimientos estacionales de hombres y ganados quedaron circunscritos a radios muy cortos que no solían traspasar, generalmente, los límites de la localidad donde estaban censados los ganados.

En los últimos años se ha avanzado de forma considerable en el reconocimiento y cartografiado de la fracción más importante del patrimonio territorial al que dio origen el régimen de explotación extensiva de la ganadería, por lo que hoy conocemos con precisión la clase y distribución de las distintas vías pecuarias a través de las cuales se desplazaban hombres y animales. Incluso se han puesto en marcha algunas acciones encaminadas a experimentar la dureza del peculiar modo de vida de los ganaderos trashumantes, acompañando en su recorrido a los últimos pastores que actualmente realizan la trashumancia. Pero aún quedan otros muchos aspectos sobre los que hay que seguir profundizando para tener una visión integral del verdadero significado de este peculiar sistema de explotación ganadera y de todos los elementos patrimoniales asociados a él. 


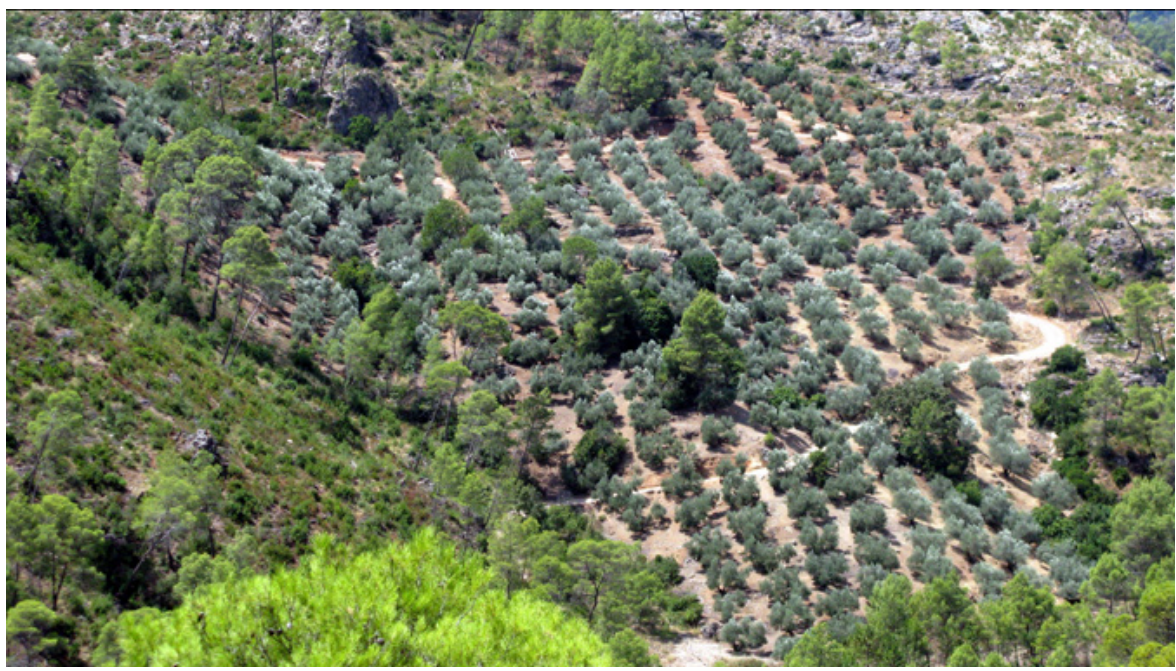

Avance del olivar en las porciones más escabrosas del territorio serrano | foto Luis Colmenero

Por esa razón consideramos hoy especialmente pertinente el establecimiento de una línea de investigación enfocada expresamente al estudio tipológico y funcional de los distintos elementos patrimoniales asociados a la explotación extensiva de la ganadería, que desde nuestro punto de vista no debería circunscribirse a las sierras de Segura y Cazorla sino comprender también el pastadero de extremo que para éstos y otros muchos ganaderos peninsulares representó la porción jiennense de Sierra Morena. Elementos tan genuinos como el hábitat de pastores y ganados, tanto en los pastaderos como a lo largo de las vías pecuarias, descansaderos, abrevaderos, etc., permanecen en un olvido incomprensible que no debe permitirse por más tiempo.

\section{DISCONTINUIDAD DEL TERRAZGO AGRÍCOLA. LA DISPERSIÓN DEL POBLAMIENTO}

Como en el conjunto de la montaña mediterránea andaluza, la expansión de la agricultura tropezó en estas sierras con las consabidas dificultades topográficas, edáficas y climáticas que imponían unas fuertes pendientes generalizadas, la debilidad agronómica de los suelos y las bajas temperaturas mínimas imperantes durante la mayor parte del año. Junto a ellas, desde mediados del siglo XIX se hizo patente una limitación jurídica mucho más severa, la cual impedía la conquista agrícola del suelo a todos aquellos que no demostraran fehacientemente su condición de propietarios de la tierra sobre la que pretendían extender los cultivos. Los procesos de delimitación y amojonamiento de los montes públicos a los que antes nos referimos, muy tímidos e imperfectos en sus primeros momentos, fueron perfeccionándose con el paso de los años hasta conseguir excluir casi por completo las fracciones del terrazgo agrícola de estos espacios, que 


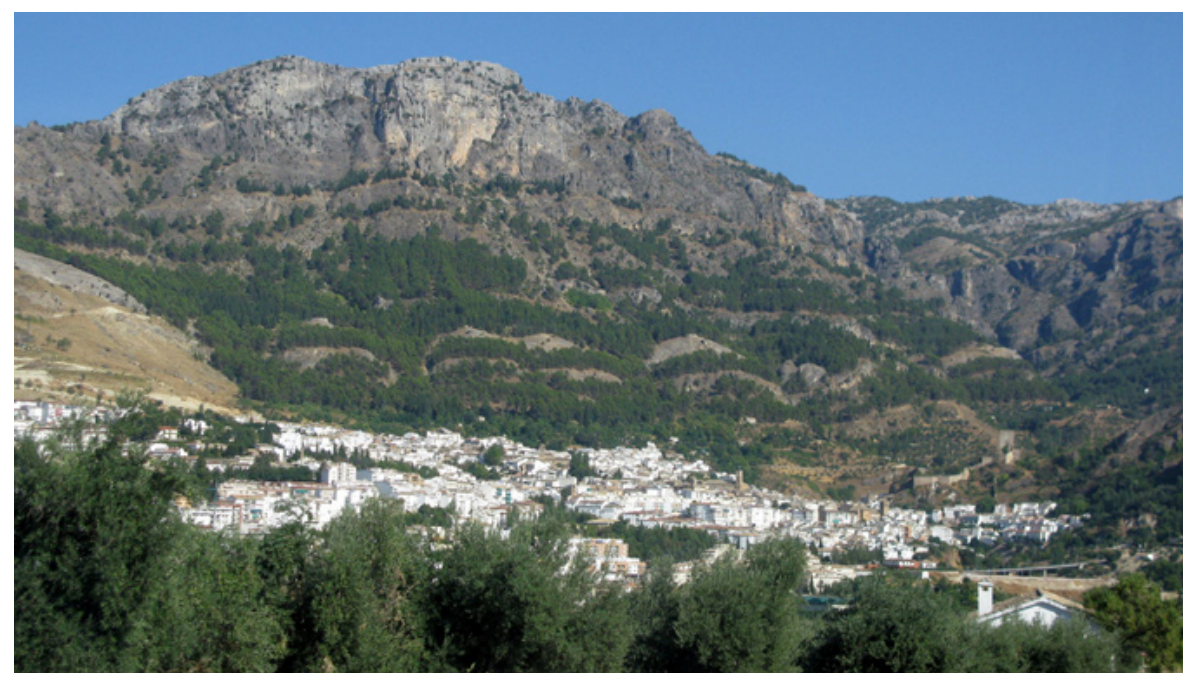

Ciudad de Cazorla, capital comarcal de la sierra de su nombre | foto Luis Colmenero

quedaron vinculados exclusivamente a los aprovechamientos agrícolas y ganaderos.

La ampliación decimonónica de la superficie labrada quedó limitada, por tanto, a las tierras de propiedad privada, bien a las que desde antiguo gozaban de esa condición jurídica, bien a las que se privatizaron tras la desamortización. Las situadas en las vertientes de los valles, incluso en las porciones más escabrosas, se ocuparon de inmediato por nuevas plantaciones de olivar, que quedaron así intercaladas para siempre en las grandes masas pinariegas o en las zonas de pastos de los montes de titularidad pública. La función del olivar en estos ámbitos no era tanto la de proporcionar una raquítica cosecha como la de hacer visible y afianzar la propiedad privada sobre esas tierras ásperas en las que muy pronto se hicieron visibles los problemas erosivos. En los fértiles fondos de valle, de suelos profundos y menos expuestos a los rigores climáticos, logró arraigar un policultivo de subsistencia mediante el cual pudo afrontarse, no sin ciertos episodios críticos, la fase de crecimiento demográfico de la segunda mitad del siglo XIX.

Pero la delimitación estricta de usos del suelo por la que tanto había peleado la naciente administración forestal no pudo resistir el fuerte empuje que se derivó del extraordinario incremento poblacional que se registró en las sierras de Segura y Cazorla durante la primera mitad del siglo XX (en la primera la población se incrementó en un 85,5\% entre 1900 y 1950, mientras que en la segunda el crecimiento fue del 82,3\% entre idénticas fechas). Excluida cualquier posibilidad de intensificación de la agricultura, la única respuesta que cabía a la pujante demanda de alimentos provenía de la ampliación del espacio agrícola a costa de las superficies ocupadas por la vegetación natural, ya fueran de uso ganadero o forestal. Y, desde luego, prescindiendo de cualquier 


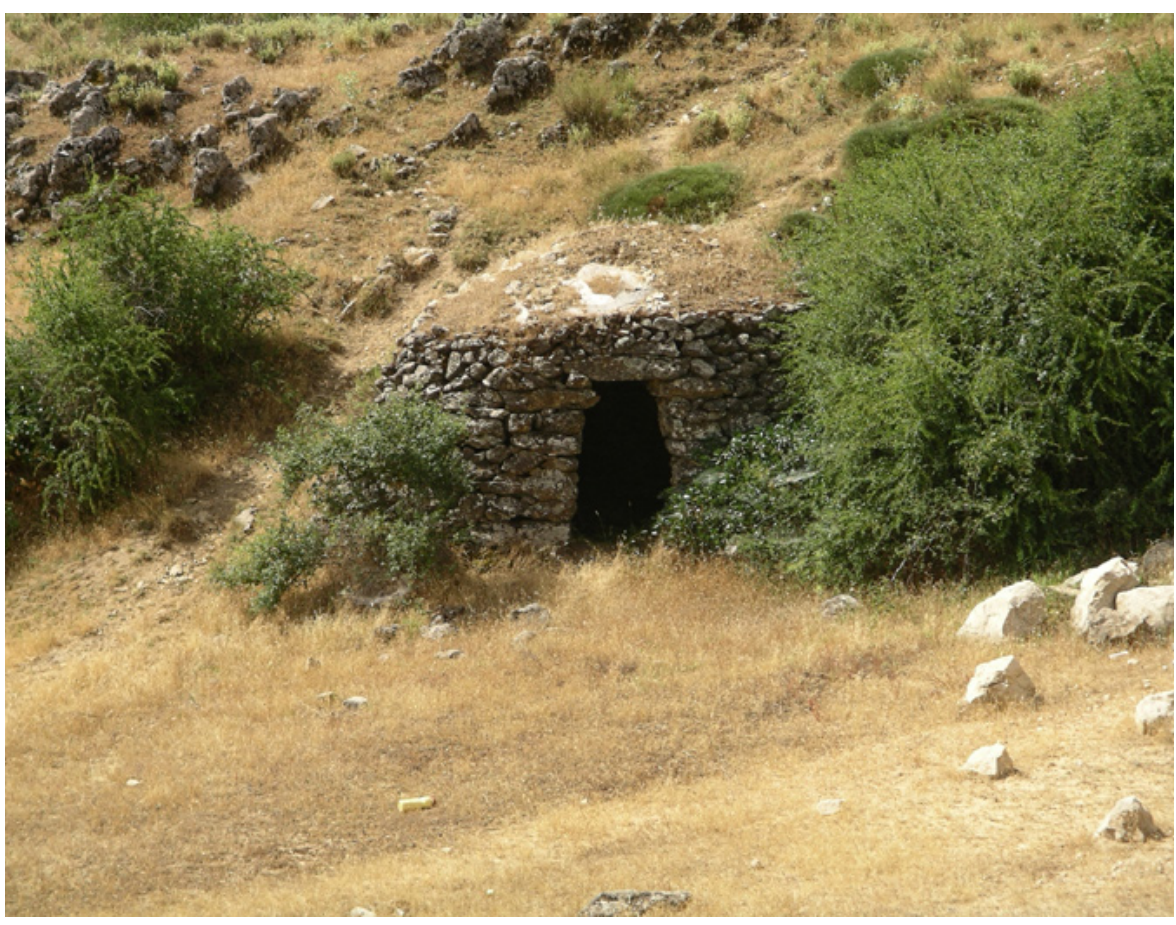

Chozo en la zona de cumbres de la sierra de Segura | foto Eduardo Araque Jiménez

consideración sobre la naturaleza jurídica de las tierras susceptibles de roturación y puesta en cultivo, buena parte de las cuales sólo eran capaces de soportar un sistema de agricultura itinerante con largos periodos de descanso del terrazgo entre un ciclo y otro de cosechas, tal y como explicaba muy bien Juan Navarro a mediados del siglo XIX (NAVARRO REVERTER, 1868).

De este modo surgieron las primeras roturaciones arbitrarias de los montes públicos, pequeñas porciones de terrazgo dispuestas entre las masas de arbolado cuya posesión no era reconocida por sus legítimos propietarios, a diferencia de las roturaciones autorizadas por las cuales los detentadores satisfacían anualmente un canon al Estado o a los ayuntamientos. Mientras que estas últimas se mantuvieron más o menos estables, sin grandes cambios en las superficies por las que se extendían, el número de roturaciones arbitrarias se disparó al compás del incremento poblacional, constituyéndose en el principal foco de conflictos y en el más grave de los problemas a los que se enfrentó la gestión de los montes públicos durante la primera mitad del siglo $X^{6}{ }^{6}$. No era para menos si tenemos en cuenta la enorme extensión que llegaban a alcanzar las tierras roturadas en distintas porciones de estos macizos en las que el uso agrícola se consideraba completamente incompatible con la conservación del medio. Sólo en los montes estatales de Santiago de la Espada y Pontones, así como en dos montes de la misma pertenencia de Hornos de Segura, llegaron a contabilizarse tras la guerra civil más de 2.000 roturadores que poseían en conjunto una superficie lige-
La bibliografía y, sobre todo, la documentación que se ha conservado sobre el particular es muy abundante pero consideramos de extraordinario interés para obtener una visión global del asunto la lectura de los trabajos de Enrique Mackay (1917) y Luis Bello (1929). 
ramente superior a las 3.000 ha, lo que arrojaba un promedio por roturador que no alcanzaba las 1,5 ha (GONZÁLEZ AGUILAR, 1961).

Muy próximas a las minúsculas parcelas de cultivo ganadas al monte, los roturadores construyeron toda clase de habitáculos elaborados con materiales provisionales, que se fueron transformando con el tiempo en viviendas estables, más o menos precarias en razón de las posibilidades económicas de cada roturador. Así se apuntaló definitivamente una estructura del poblamiento única en Andalucía, integrada por centenares de minúsculas aldeas que se dispersaban por cada uno de los términos municipales serranos, que llegaron a aglutinar en algunos momentos un mayor número de habitantes que la propia cabecera del término. En su localización se tuvieron en cuenta las variadas posibilidades que ofrecía el medio, y de una manera muy especial la proximidad a alguna fuente $u$ otra corriente permanente que les permitiera a los vecinos disponer de agua durante todo el año. El nomenclátor que acompañaba al censo de población de 1930, uno de los más exhaustivos que se conocen sobre estas sierras, daba cuenta de la atomización extrema que alcanzaba el hábitat en gran parte de los municipios serranos, particularmente en aquellos situados en el extremo nororiental de estos macizos. Entre todos los municipios destacaba Santiago de la Espada $\left(484,7 \mathrm{~km}^{2}\right)$, donde se contabilizaban 116 entidades de población, seguido de Segura de la Sierra $\left(224,4 \mathrm{~km}^{2}\right)$, con 104 entidades y Pontones $\left(197,4 \mathrm{~km}^{2}\right)$, con 71 entidades.

Todo este entramado territorial entró en crisis y se descompuso de una forma alarmante a partir del inicio de los años cuarenta, coincidiendo con la puesta en marcha de los trabajos de repoblación forestal que de forma sistemática se desarrollaron en estas sierras en ésa y en las décadas siguientes. A pesar de la fuerte conflictividad social que suscitó la actuación reforestadora, por cuanto suponía la erradicación de viviendas y tierras de cultivo que eran el único medio de habitación y de subsistencia de multitud de familias serranas (ARAQUE JIMÉNEZ; CRESPO GUERRERO, 2012), nada pudo hacerse por evitar la desaparición de centenares de caseríos, cortijadas y aldeas. Como tampoco pudo frenarse el éxodo masivo que de forma voluntaria emprendieron otros miles de familias en esos mismos momentos, comenzando por aquellas que residían en las entidades de población más pequeñas, donde las condiciones de existencia se habían vuelto realmente insoportables.

Aunque no lo pretendiera, un trabajo realizado a finales de los años cincuenta en Santiago de la Espada (DEBÓN TORTOSA, 1957), cuyas conclusiones eran perfectamente extrapolables al resto de los municipios serranos, daba cuenta de esas estremecedoras condiciones bajo las que se desenvolvía la vida de la inmensa mayoría de la población, sobre todo de la que residía en los núcleos más diminutos. Sólo una ínfima parte de ellos disponían de luz eléctrica, pero en tan pésimas condiciones que apenas disponían de 
7

Para ayudar a entender la trascendencia de fenómeno migratorio baste con un solo dato: la sierra de Segura había disminuido en casi la mitad sus efectivos demográficos entre 1960 y 1986, mientras que en la sierra de Cazorla, entre las mismas fechas, esas pérdidas habían superado el 30\%. Sobre el particular puede verse Araque Jiménez (1990). unas horas para disfrutar de ella; el abastecimiento de agua se realizaba en las fuentes próximas a las aldeas o directamente del río, cuyas aguas también servían para lavar y asearse; la inmensa mayoría de las viviendas carecían de ventilación y en ellas compartían un mismo espacio hombres y animales, dando origen a un clima de insalubridad en el que eran muy frecuentes las enfermedades; en fin, un mísero panorama vital en el que se carecía de los más elementales servicios a los que tenía derecho cualquier ser humano, máxime bajo un régimen político que se autoproclamaba defensor de la justicia social. Aunque no suele formar parte de la causalidad general que se invoca a la hora de explicar la amplitud del fenómeno migratorio en estas sierras ${ }^{7}$, estamos convencidos de que estas pésimas condiciones de existencia, en muchos casos, pesaron bastante más que la falta de oportunidades laborales a la hora de tomar una decisión individual de tanta trascendencia como la emigración definitiva.

Ese abandono masivo de amplias porciones del territorio serrano dio origen de forma súbita al florecimiento de unos paisajes de absoluta desolación en los que las viviendas completamente derruidas o semiderruidas se entremezclaban con los campos de cultivo y otros elementos del sistema agrario (caminos, acequias, eras, etc.), en los que la invasión de la vegetación espontánea avanzaba a un ritmo vertiginoso, señal inequívoca de la carencia de cualquier clase de cuidados culturales. El mecanismo de la expropiación forzosa al que se recurrió masivamente para dotar de mayor eficacia a la política de repoblación forestal impidió conservar la propiedad del terrazgo agrícola y de sus viviendas asociadas, de manera que en numerosas cortijadas y aldeas no fue posible, ni siquiera, reconstruir y recuperar como viviendas secundarias esa fracción del hábitat.

Puesto que no se ha realizado hasta el momento, resultaría muy oportuno abordar un estudio en profundidad no ya sólo de las causas de la descomposición de este singular sistema de poblamiento sino también de sus orígenes y evolución a lo largo de los dos últimos siglos, diferenciando las formas y funciones de cada uno de los grandes tipos de hábitat en razón de su vinculación con el sistema dominante de explotación del territorio: agrícola, ganadero y forestal. Así mismo sería de una enorme utilidad el análisis pormenorizado de los distintos elementos que conforman las tramas urbanas de estos diminutos núcleos de población, desde las precarias viviendas como ámbitos de uso individual, hasta otro tipo de elementos insertos en los raquíticos planos urbanos tales como hornos, fuentes, lavaderos, etc., en tanto que espacios de utilización comunitaria. Consideramos que este tipo de trabajo puede tener una gran utilidad de cara a la identificación y el señalamiento de todos aquellos bienes patrimoniales que deberían ser objeto de catalogación por su excepcionalidad constructiva o por su simbolismo. 


\section{CONCLUSIONES}

A pesar de que se han dado pasos muy importantes durante los últimos años en pos del conocimiento científico de las sierras de Cazorla, Segura y las Villas, a día de hoy quedan múltiples y variados aspectos sobre los que la investigación ha progresado mucho más lentamente. Hasta ahora han primado los aspectos naturalistas a la hora de explicar la excepcionalidad de estos macizos montañosos, en lo que ha influido, sin duda, el establecimiento en 1986 de la figura de Parque Natural sobre una buena parte de estas sierras orientales jiennenses. Se olvida muy a menudo que fue precisamente en el momento de la declaración del espacio protegido cuando se apostó abiertamente por compatibilizar la preservación del medio con el inexcusable desarrollo económico que requería la población que más había contribuido con su generoso esfuerzo a la creación de aquella figura. Era, sencillamente, una cuestión de estricta justicia social.

En este contexto de armonización de intereses es en el que cobra todo su significado cualquier propuesta de análisis y evaluación del patrimonio rural acumulado durante siglos en estas sierras. Ante todo porque constituye una parte esencial de las señas de identidad comarcales que no puede permanecer en el olvido por más tiempo mientras asistimos impasibles a su deterioro y destrucción. Pero también porque esa fracción patrimonial puede convertirse en un activo fundamental de desarrollo a través de programas encaminados a su divulgación. A nuestro modo de ver, ésta es una de las acciones prioritarias que deberían incorporarse con urgencia a las nuevas propuestas de relanzamiento socioeconómico del espacio protegido.

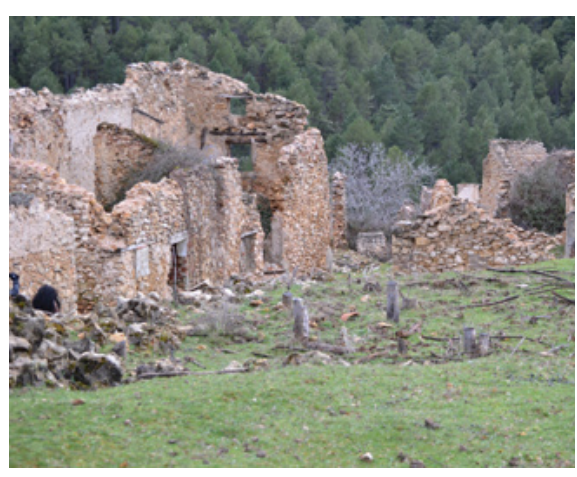

Hábitat abandonado en la Sierra | foto Eduardo Araque Jiménez

\section{Nota de la redacción revista ph}

Agradecemos a las siguientes personas su colaboración en esta sección aportando imágenes de la Sierra de Cazorla, Segura y las Villas que fueron publicadas en el perfil de Facebook del IAPH entre los meses de abril y junio de 2013:

Julio Alguacil Gómez | Francisco Álvarez Espada | Luis Colmenero Ruiz | Antonio Estrella Lara | Víctor Fernández Salinas | Antonio García García | Juan Manuel Velázquez Jiménez 
- ARAQUE JIMÉNEZ, E. (1990) Sierras de Segura y Cazorla. En VV. AA. Geografía de Jaén. Granada: Edit. Andalucía, 1990, pp. 991-1018

- ARAQUE JIMÉNEZ, E. (2011) Le patrimoine forestier du Parc Naturel des Sierras de Cazorla, Segura et Las Villas. Propositions d'intervention. En COLLOQUE patrimonialiser la nature: valeurs et processus (Université de Pau et des Pays de l'Adour, 7, 8 y 9 septiembre de 2011) (inédito)

- ARAQUe JIMÉnEZ, E. (2012) El patrimonio de los montes del Parque Natural de las Sierras de Cazorla, Segura y Las Villas. Contrato de investigación establecido entre la Universidad de Jaén y la Diputación Provincial de Jaén (documento inédito)

- ARAQUE JIMÉNEZ, E.; CRESPO GUERRERO, J. M. (2012) Reforestation et conflit social dans les monts du sud de l'espagne. Le cas de la Sierra de Segura (Province de Jaén, Andalousie). En COLLOQUE International Fôret et montagne. Evolution et aménagement. Groupe d'Histoire des forêts françaises. Chambéry (18 al 20 de septiembre de 2011) (en prensa)

- ARGÜELlES ÁlVAREZ, R. (1961) Estudio económico exhaustivo de la ganadería de Santiago de la Espada (Jaén). Usos pastoriles, costos, distribución entre ganaderos, etc. Proyecto fin de carrera. Escuela Técnica Superior de Ingenieros de Montes. Universidad Politécnica de Madrid. Original mecanografiado

- BARó, F. (1915) Las pequeñas industrias forestales. España Forestal, n. ${ }^{\circ}$ 5, 1915, pp. 103-106

- BELLO, L. (1929) Viaje por las escuelas de España. Vol. IV. Más Andalucía. Madrid: Cía. Iberoamericana de Publicaciones, 1929

- BRIONES, F. (1946) El pantano del Tranco de Beas. Revista de Obras Públicas, 1946, 94, tomo I, n. ${ }^{\circ} 2773$, pp. 211-219

- BRIONES, F. (1946) El pantano del Tranco de Beas. Revista de Obras Públicas, 1946, 94, tomo I, n. ${ }^{\circ} 2774$, pp. 264-273

- CRUZ AGUILAR, E. DE LA (1981) La provincia marítima de Segura de la Sierra. Boletín del Instituto de Estudios Giennenses, n. ${ }^{\circ} 107,1981$, pp. 51-84

- DEBón TORTOSA, S. (1957) Ensayo de educación fundamental en la comarca culturalmente retrasada de Santiago de la Espada (Jaén). Boletín de la Junta Nacional contra el Analfabetismo, n. ${ }^{\circ}$ 5,1957, pp. 14-44

- GARRIDO GONZÁLEZ, J. L.; GARRIDO SÁNCHEZ, J. L. (2003) Cultura popular en la Sierra de Segura. Jaén: Publicaciones de la Universidad de Jaén, 2003
- GONZÁLEZ AGUILAR, M. (1961) Estudio estadístico y económico-social de la población instalada en los montes del Estado de las Sierras de Cazorla y Segura. Proyecto fin de carrera. E. T. Superior de Ingenieros de Montes. Universidad Politécnica de Madrid. Original mecanografiado

- GIL OLCINA, A. (2001) Del Plan General de 1902 a la planificación hidrológica. Investigaciones Geográficas, n. ${ }^{\circ}$ 25, 2001, pp. 5-32

- IDÁÑEZ, F. (1995) Oficios tradicionales de la Sierra de Segura: pegueros y mereros. Demófilo. Revista de Cultura Tradicional, n. ${ }^{\circ}$ 14, 1995, pp. 55-74

- IDÁÑEZ, F. (1999) El transporte fluvial de la madera de los montes de Jaén. El toro de caña, n. ${ }^{\circ} 4$, 1999, pp. 305-326

- LÓPEZ ARANDIA, M. A. (2012) Maderas del Rey. Aprovechamientos madereros en la provincia marítima de Segura de la Sierra. En ARAQUE, E.; MOYA, E. Aprovechamientos madereros en los montes jiennenses (Siglos XVIII- XX). Jaén: Publicaciones de la Universidad de Jaén, 2012, pp. 13-71

- MACKAY, E. (1917) La Sierra de Cazorla bajo su aspecto forestal. Madrid: Imprenta de Julio Cosano, 1917

- MOLINA ROdRÍGUEZ, F. (1946) Proyecto de ordenación del grupo de montes en resinación de la Serranía de Cazorla (Jaén). Proyecto fin de carrera. Madrid. Escuela Especial de Ingenieros de Montes. Original mecanografiado

- MORENO FERNÁNDEZ, J. R. (2001) Las áreas rurales de montaña en la España del siglo XVIII: el caso de las sierras del sur de La Rioja. Revista de Historia Económica, n. ${ }^{\circ} 19,2001$, pp. 61-84.

- MOYA GARCíA, E. (2007) El esparto en el sureste de la provincia de Jaén. En Araque JIMÉNEZ, E.; SÁNCHEZ MARTÍNEZ, J. D. Los montes andaluces y sus aprovechamientos: experiencias históricas y propuestas de futuro. Jaén: Publicaciones de la Universidad de Jaén, 2007, pp. 151-176

- NAVARRO REVERTER, J. (1868) Correspondencia. Revista Forestal, Económica y Agrícola, tomo I, 1868, pp. $342-345$ y $423-430$

- NIETO OJEDA, R. (2006) Historias, leyendas, anécdotas y personajes de la Sierra de Cazorla. Cazorla: Ediciones R. Nieto, 2006

- PUIG, I. (1960) El Plan Jaén. Descripción de lo que es y será la provincia de Jaén. Barcelona: Ifiba, 1960

- QUINTERO GONZÁLEZ, J. (2004) La Carraca. El primer arsenal ilustrado español. Madrid: Ministerio de Defensa, 2004 
- RUBIO DE LUCAS, J. L. (1993) Alcaraz, Cazorla y Segura. Cuadernos de la trashumancia, n. ${ }^{\circ}$ 10. Madrid: ICONA, 1993

- SÁNCHEZ MARTÍNEZ, J. D. et ál. (2008) La repoblación forestal de Sierra Morena, Jaén, (1940-1984). Anales de Geografía de la Universidad Complutense, n. ${ }^{\circ} 28,1,2008$, pp. 105-131

- SIMÓN, E. DE (1953) Aprovechamientos de los montes de Jaén. Montes, n. ${ }^{\circ}$ 54, 1953, pp. 495-501

- VALLVÉ BERMEJO, J. (1969) La división territorial de la España musulmana. La Cora de Jaén. Al-Andalus. Revista de las Escuelas de estudios árabes de Madrid y Granada, vol. 34, 1969, pp. 55-82

- VILLEGAS DÍAZ, L. R.; GARCÍA SERRANO, R. (1976) Relación de los pueblos de Jaén, de Felipe II. Boletín del Instituto de Estudios Giennenses, n. ${ }^{\circ} 88-89,1976$, pp. 9302 